\title{
A elite empresarial e as instituições democráticas: cultura política, confiança e padrões de ação política
}

\author{
ב \\ Paulo Roberto Neves Costa \\ Departamento de Ciências Sociais \\ Universidade Federal do Paraná \\ Editor-chefe da Revista de Sociologia e Política
}

\begin{abstract}
Resumo: O objetivo deste artigo é analisar a concepção de democracia, a relação com as instituições democráticas, o grau de confiança nelas depositado e alguns aspectos dos padrões de ação política da elite empresarial brasileira nos dias de hoje. Utilizamos a noção de elite empresarial, composta por aqueles que exercem a direção de entidades de representação dos diversos setores do empresariado, tendo por referência, portanto, não propriamente o critério do poder econômico ou da direção de grandes empresas, como é usual nos estudos sobre elites econômicas, mas sim o da representação política, ou seja, os dirigentes que foram eleitos pelos membros das entidades empresariais e exercem a articulação dos interesses de seus representados. Os dados provêm de entrevistas junto a dirigentes de entidades de diversos setores, de distinta natureza (sindical e associativa) e amplitude de ação (estadual ou nacional), verificando não apenas as opiniões, mas também as suas justificativas, dando aos dados uma dimensão qualitativa, nem sempre utilizada nos estudos de cultura política. Constatamos que há por parte da elite empresarial brasileira uma forte adesão à democracia, muito maior do que a da população em geral, uma posição favorável às formas de participação política, além de um grau maior de confiança e de satisfação com as instituições democráticas.
\end{abstract}

Palavras-chave: empresariado; elite empresarial; cultura política; democracia; confiança

\begin{abstract}
The aim of this article is to analyze the concept of democracy, the relationship with democratic institutions, the trust placed in them and some aspects of the patterns of political action of the business elite in Brazil nowadays. We use the notion of the business elite, composed by those who are engaged in the direction of representative entities of various sectors of business, therefore, not exactly the criteria of economic power or direction of large companies, as is usual in studies on economic elites, but that of political representation: the leaders who were elected by members of the entities engaged in the business and articulate the interests of their constituents. Data come from interviews with directors of entities from various sectors distinct nature (trade union and associative) and range of action (state or national), checking not only the opinions but also their justifications or rationale, giving a qualitative aspect to data, rarely used in studies of political culture. We realized that the business elite has a strong adherence to democracy higher than the general population, it is favorable to political participation and a high degree of trust and satisfaction with Brazilian democratic institutions.
\end{abstract}

Keywords: entrepreneurs; business elite; political culture; democracy; trust 
COSTA, P. R. N. A elite empresarial e as instituições democráticas: cultura política... Introdução ${ }^{1}$

O que os empresários pensam sobre a democracia? Qual o seu grau de adesão a este regime? Qual é a relação entre as características desta adesão e a avaliação sobre o funcionamento das instituições democráticas? Qual é o grau de confiança que permeia as relações do empresariado com a política e com as próprias atividades empresariais? Os empresários estão satisfeitos com as instituições democráticas brasileiras? Em relação a tais aspectos, quais seriam as semelhanças e diferenças em relação à população em geral? 0 que se verifica quando comparamos esses elementos da cultura política do empresariado brasileiro com alguns dos seus padrões de ação política? E, por fim, como são justificadas e fundamentadas tais atitudes políticas?

Este artigo traz contribuições para o tratamento destas questões, cujas respostas suscitam alguns aspectos metodológicos e teóricos que devem ser, ainda que brevemente, estabelecidos desde já. Em outro artigo, apresentei argumentos em relação à importância da análise da cultura política de grupos ligados às atividades empresariais e mais particularmente da elite empresarial (COSTA e ENGLER, 2008).

Sumariamente, tais argumentos são os seguintes: 1- o estudo da cultura política de grupos específicos e menores que assumem posições relevantes em termos de poder econômico e político é sociologicamente muito relevante, dada a sua importância para a compreensão de seus padrões de ação política e de seu impacto no funcionamento e no desenvolvimento do regime político democrático; 2- na literatura sobre cultura política predominam estudos sobre o conjunto da população 3 - e, no caso do empresariado, a restrição da pesquisa àqueles que ocupam posição privilegiada em relação à propriedade e ao controle do capital, ou seja, a elite econômica, poderia implicar em prejuízos para a análise sociológica, em especial quando a questão remonta às instituições democráticas:

“(...), o conceito de elite empresarial e a forma como ele é aqui operacionalizado caracterizam. se pelos seguintes aspectos: em primeiro lugar, refere-se a um grupo que possui ou controla diversos tipos de capital e, portanto, possui poder econômico relevante frente à sociedade, mas dentro deste grupo são considerados apenas aqueles que se destacam no processo de representação política do próprio grupo. Isso permite que a elite empresarial seja considerada mais do que uma elite econômica, mas também como uma elite política, entendida como aquela que é composta pelos que ocupam os principais cargos políticos. Enfim, o que a distingue é mais do que a posse ou controle do capital, mas, sobretudo o exercício da representação política do grupo que possui tal característica, seja diante de seus pares, ocupando o cargo mais importante na direção de uma entidade representativa, seja no

\footnotetext{
${ }^{1}$ Este artigo decorre de pesquisas relativas à Bolsa de Produtividade do CNPq, ao qual expresso os agradecimentos. Agradeço também aos pesquisadores do Grupo de Estudo Empresariado e Ação Política, vinculado ao Núcleo de Pesquisa em Sociologia Política Brasileira da Universidade Federal do Paraná, pelo trabalho de coleta dos dados e também a todos os entrevistados pela sua disposição em colaborar.

${ }^{2}$ Ver, por exemplo, o recente livro organizado por José Álvaro Moisés (2010). 
OPINIÃO PÚBLICA, Campinas, vol. 18, nº 2, novembro, 2012, p. $452-469$

exercício da defesa dos interesses empresariais frente ao Estado e aos demais grupos políticos da sociedade" (COSTA e ENGLER, 2008).

A pesquisa subjacente às análises aqui reportadas procura articular questões relacionadas aos estudos sobre o empresariado, sobre as elites políticas e sobre a cultura política. Para tanto, tal pesquisa baseou-se na aplicação de um questionário com questões fechadas e abertas aos dirigentes de entidades de representação do empresariado, cujos aspectos metodológicos são apresentados à frente.

Morlino (2010) defende a importância dos estudos sobre atitudes políticas e sobre confiança para a teoria da democracia, a necessidade de se considerar não apenas a massa como também as elites e também a necessidade de fazê-lo através de surveys. Na pesquisa subjacente a este artigo, procuramos contribuir para a verificação de como tais variáveis se dão no interior de uma importante elite e através de um survey, ao qual foram agregadas abordagens qualitativas.

Os resultados obtidos indicam que há, por parte da elite empresarial brasileira, uma posição positiva em relação ao exercício da ação política, uma forte adesão à democracia e um grau maior de confiança e de satisfação com as instituições democráticas em comparação à população em geral. Por sua vez, alguns aspectos dos seus padrões de ação política refletem tal conjunto de atitudes políticas. Nas próximas seções, detalhamos os procedimentos metodológicos e apresentamos os dados da pesquisa sobre os valores políticos e os padrões de ação política da elite empresarial brasileira e, por fim, nossas considerações finais.

\section{A cultura política da elite empresarial brasileira}

$\mathrm{Na}$ sua maior parte, os estudos sobre as atitudes políticas das elites políticas, ou mesmo da população em geral, possuem uma natureza quantitativa, ou seja, procura-se verificar as variações e a dinâmica das opiniões em relação a assuntos diversos. Embora forneça uma série de dados muito importantes, a pesquisa quantitativa não permite verificar de forma mais detalhada os fundamentos e as causas das atitudes e suas possíveis implicações sobre as ações políticas. Neste sentido, nossa pesquisa buscou verificar algo que não havia sido contemplado em pesquisas anteriores a respeito da elite empresarial no Brasil $^{3}$ ou seja, as justificativas e as fundamentações para as avaliações e posicionamentos, enfim, para as atitudes e as ações da elite empresarial frente à democracia brasileira atual.

Para tanto, no questionário aplicado em nossa pesquisa, procuramos não apenas mensurar os aspectos quantitativos de variáveis como o grau de adesão, as concepções de democracia e as avaliações sobre o funcionamento das instituições democráticas no Brasil e suas perspectivas, mas também apreender as suas justificativas. Estas nos permitiram contribuir para a fundamentação e o aprimoramento da análise da cultura política e da ação política do empresariado.

\footnotetext{
${ }^{3}$ Ver Costa (2005a, 2005b) e Costa e Engler (2008).
} 
COSTA, P. R. N. A elite empresarial e as instituições democráticas: cultura política...

O questionário foi montado a partir das seguintes questões: concepções sobre política, democracia e reforma política; adesão à democracia; consolidação da democracia no Brasil; confiança em relação às instituições democráticas brasileiras; relação entre a democracia e os interesses empresariais; formas de ação política do empresariado na democracia; avaliação sobre alguns processos relativos à economia; aspectos gerais da trajetória política dos presidentes de entidade e, por fim, estratégias utilizadas nas eleições de 2010 em relação aos candidatos dos diversos cargos em disputa. 0 questionário foi aplicado entre 2010 e o início de 2011. Os comentários a seguir estão centrados nos aspectos relacionados às questões levantadas no início do artigo: o grau e as justificativas para a adesão à democracia, a avaliação sobre as instituições políticas, o grau de confiança, tanto em relação às atividades empresariais como em relação às instituições políticas, e alguns aspectos dos seus padrões de ação política.

Deve-se registrar que alguns questionários foram respondidos por vice-presidentes, diretores e altos assessores das entidades. Tal fato em nada altera a utilidade dos dados obtidos, já que este artigo trata de aspectos estritamente pessoais dos presidentes (trajetória social, trajetória educacional, atributos adstritos ou adquiridos, etc.), como é comum nos estudos sobre elites. Além disso, em geral, os membros de uma elite política têm seus assessores específicos, os quais fazem parte de sua própria trajetória e atuação enquanto elite. Por fim, tais pessoas fazem parte do círculo mais próximo ao presidente e estão ligadas à atividade de representação política, o que implica em uma posição também institucional e não exclusivamente individual.

Os dados utilizados referem-se às respostas dadas pelos dirigentes das seguintes entidades, por ordem alfabética4:

- Associação Brasileira da Indústria do Café (ABIC): criada em 1973, visa representar aproximadamente 500 empresas da indústria de torrefação e moagem em âmbito nacional;

- Associação Brasileira de Infraestrutura e Indústrias de Base (ABDIB): criada em 1955, representa o setor industrial ligado à indústria de base ${ }^{5}$;

\footnotetext{
4 Todas as entidades aqui contempladas possuem alguma forma de divulgação eletrônica de suas atividades, o que permite a consulta sobre maiores detalhes de sua história e de seu funcionamento, os quais, neste momento não cabe apresentar.

${ }^{5}$ Entre as associadas estão mais de 150 empresas, entre elas AES Eletropaulo - Metropolitana Eletricidade de São Paulo S.A.; Alstom Brasil Energia e Transporte Ltda.; Alstom Hydro Energia Brasil Ltda.; Andrade Gutierrez S.A.; Banco Do Brasil S.A.; Bardella S.A. Indústrias Mecânicas; Bombardier Transportation Brasil Ltda.; Brasil Telecom S.A.; Brastubo Construções Metálicas Ltda.; Brvias; Caixa Econômica Federal; Camargo Corrêa S.A.; CCR - Companhia De Concessões Rodoviárias; CEDAE - Companhia Estadual de Água e Esgoto do Estado do Rio de Janeiro; CEMIG - Companhia Energética De Minas Gerais; CHESF - Companhia Hidro Elétrica do São Francisco; Chevron Brasil Petróleo Ltda.; COMGÁS - Companhia de Gás de São Paulo; Construtora Barbosa Mello S.A; Construtora Norberto Odebrecht; Construtora Queiroz Galvão S.A.; CPFL Energia S.A.; CR Almeida S.A Engenharia de Obras; CTEEP - Cia. de Transmissão de Energia Elétrica Paulista; CVRD - Companhia Vale do Rio do Doce; Delta Construções S.A.; Eletrobrás - Centrais Elétricas Brasileiras S.A.; Eletronorte - Centrais Elétricas do Norte do Brasil; Eletronuclear; Eletrobrás Termonuclear S.A; Ericsson; Ernst \& Young Assessoria Empresarial Ltda.; Furnas Centrais Elétricas S.A.; Galvão Engenharia S.A.; General Eletric do Brasil S.A.; G\&R Gestão Empresarial S.C. Ltda.; Grupo Oi; Light Serviços de Eletricidade S.A.; OAS; Petrobras; PGS Investigação Petrolífera Ltda.; Pricewaterhouse Coopers; Promon Engenharia Ltda.; Repsol Ypf Brasil S.A.; Sabesp - Cia de Saneamento Básico do Estado de São Paulo; Samsung Eletrônica da Amazônia Ltda; Serveng Civilsan S.A.; Shell do Brasil S.A.; Siemens S.A.; Telefonica - Telecomunicações de São Paulo S.A.; Toshiba Sistemas de Transmissão e Distribuição do Brasil Ltda.; Unibanco - União de Bancos Brasileiros S.A.
} 
OPINIÃO PÚBLICA, Campinas, vol. 18, nº 2, novembro, 2012, p. $452-469$

- Associação Brasileira de Marketing e Negócios (ABMN): criada em 1971, representa empresas ligadas à comunicação;

- Associação Comercial de São Paulo (ACSP): entidade criada em 1884, bastante reconhecida no processo de representação empresarial não restrito ao comércio e à cidade de São Paulo;

- Associação Nacional de Exportadores de Sucos Cítricos (Citrus): entidade nacional que representa grandes empresas ligadas à agricultura e à indústria e exportação de sucos ${ }^{7}$;

- Associação Paranaense de Obras Públicas (APEOP.PR): criada em 1960, é voltada para a representação dos empreiteiros do Paraná;

- Confederação Nacional das Instituições Financeiras (CNF): entidade sindical criada em 1985 para representar diversas e importantes entidades do setor financeiro ${ }^{8}$;

- Confederação Nacional dos Transportes (CNT): entidade sindical de terceiro grau do setor de transporte ${ }^{9}$;

- Federação das Associações Comerciais do Paraná (FACIAP): entidade que visa representar 288 associações comerciais do todo o estado ${ }^{10}$;

- Federação das Indústrias do Estado do Paraná (FIEP): federação sindical da indústria paranaense, cujo presidente integrou o Conselho de Desenvolvimento Econômico e Social (CDES) e a direção da Confederação Nacional da Indústria (CNI);

- Federação das Indústrias do Rio de Janeiro (FIRJAN): entidade sindical de segundo grau da indústria do Rio de Janeiro;

- Federação do Comércio de Bens, Turismo e Serviços Roraima (FECORMECIO-RR): entidade sindical de segundo grau do setor em Roraima;

- Federação do Comércio do Estado de Goiás (FECOMERCIO-GO): entidade sindical de segundo grau do comércio e dos serviços do estado de Goiás;

\footnotetext{
${ }^{6}$ Entre as empresas que fazem parte desta associação estão: Active International do Brasil; Ambev; Banco Bradesco; Banco do Brasil; Banco Itaú; Bristol-Myers Squibb; Caixa Econômica Federal; Casas Bahia; Cyrela; Danone; Dm9ddb Publicidade; Doria Associados; DPZ Propaganda; Editora Globo; ESPN Brasil; Fiat Automóveis; Fischer América; Glaxosmithkline Brasil; Golden Cross; Grupo Bertin; Habib's; HSBC; Ibope; Indoormidia; Jornal O Dia; L'oreal Brasil; Losango; Mastercard; Mccann Erickson Publicidade; MPM Propaganda; Natura; Nestlé; O Boticário; Rede Record; SBT; Shell Brasil; TIM; Rede Globo; Unilever Brasil; Vivo; Volkswagen; Y\&R Brasil. Esta informação foi coletada em: <http://www.abmn.com.br/abmn/abmn.asp>. Acesso em: 08 maio 2009 .

${ }^{7}$ As empresas associadas são Citrosuco, Cutrale, Citrovita e Louis Dreifus Commodities.

${ }^{8}$ As entidades filiadas são: Associação Brasileira de Bancos (Abbc); Associação Brasileira das Entidades de Crédito Imobiliário e Poupança (Abecip); Associação Brasileira das Empresas de Leasing (Abel); Associação Nacional das Instituições de Crédito, Financiamento e Investimento (Acrefi); Associação Brasileira das Entidades dos Mercados Financeiro e de Capitais (Anbima); Associação Nacional das Corretoras e Distribuidoras de Títulos de Valores, Câmbio e Mercadorias (Ancord); Federação Brasileira de Bancos (Febraban).

9 As entidades filiadas são: Cepimar - Federação das Empresas de Transportes Rodoviários dos Estados do Ceará, Piauí e Maranhão; Fepasc . Federação das Empresas de Transporte de Passageiros dos Estados do Paraná e Santa Catarina; Fetergs . Federação das Empresas de Transportes Rodoviários do Estado do Rio Grande do Sul; Fetrabase - Federação das Empresas de Transportes dos Estados da Bahia e Sergipe; Fetram - Federação das Empresas de Transporte de Passageiros do Estado de Minas Gerais; Fetramar - Federação das Empresas de Transporte Rodoviário de Passageiros dos Estados de Mato Grosso, Mato Grosso do Sul e Rondônia; Fetranorte - Federação das Empresas de Transportes Rodoviários da Região Norte; Fetranspor Federação das Empresas de Transportes de Passageiros do Estado do Rio de Janeiro; Fetransportes - Federação das Empresas de Transportes do Estado do Espírito Santo; Fetrasul . Federação das Empresas de Transportes Rodoviários do Sul e CentroOeste do Brasil; Fetronor - Federação das Empresas de Transporte de Passageiros do Nordeste.

${ }^{10}$ As associações comerciais filiadas contemplam mais de 40 mil empresas em todo o Paraná. A Faciap, juntamente com a FIEP, criou e mantém a Rede de Participação Política, voltada para a mobilização e a valorização da participação da população na política e no processo decisório. Ver: <http://www.faciap.org.br/portal/> e <www.participacaopolitica.org.br>. Sobre a Rede, ver Costa e França (2012).
} 
COSTA, P. R. N. A elite empresarial e as instituições democráticas: cultura política...

- Federação do Comércio do Estado de São Paulo (FECOMÉRCIO.SP): entidade sindical de segundo grau do comércio e dos serviços do estado de São Paulo;

- Sociedade Rural Brasileira (SRB): criada em 1919, é uma associação que representa a "classe rural" e que se apresenta como "....agente negociador político do agronegócio".

Observa-se que os membros da elite empresarial que foram entrevistados estão ligados a entidades de representação de vários e importantes setores e atividades, de estados de maior e menor relevância econômica e política e contemplam as duas principais formas institucionais e âmbitos de representação: a sindical e a associativa, a nacional e a estadual. Muitas destas entidades representam diversas outras do mesmo setor ou de âmbitos mais regionais. Enfim, trata-se de um grupo de entidades bastante diversificado e que contempla os principais aspectos da forma de representação do empre sariado no Brasil. Portanto, todos os entrevistados enquadram-se dentro do que estamos considerando como elite empresarial e nesta possuem papel relevante. As respostas serão comentadas de forma agregada e sem a identificação dos respectivos respondentes, conforme foi assegurado aos entrevistados.

Por último, a referência do conceito de elite empresarial à questão do exercício da representação, no caso, a direção de entidades representativas, em nada significa discutir sobre o quanto e de que forma tal elite efetivamente representa o conjunto do empresariado, dado que tal análise só poderia ser feita se consideradas, de um lado, a agenda de interesses e as demandas levantadas pelas entidades e, de outro, as suas ações concretas no âmbito do processo decisório. Não são estas as questões que nos propusemos tratar neste artigo e na pesquisa subjacente. Além disso, embora a importância econômica dos setores empresariais aos quais essas entidades estão vinculadas e delas próprias seja bastante clara, isso não significa que procedemos como o senso comum, que tende a associar mecanicamente a relevância econômica do setor à entidade que supostamente o representaria. O processo de representação é muito mais complexo e não pode ser reduzido ao fato de que, por exemplo, se a atividade industrial de um dado estado tem grande participação no PIB, a entidade deste setor efetivamente representa de forma completa todas as dimensões daquela atividade no âmbito da política.

\section{Elite empresarial e democracia: atitudes políticas e justificativas}

O questionário utilizado pela pesquisa contemplou perguntas através das quais verificamos o que se entende por democracia e quais seriam os seus aspectos essenciais e/ou desejáveis ou dispensáveis e/ou indesejáveis, sempre acompanhadas do pedido de uma justificativa ${ }^{11}$. Por um lado, a democracia representativa, ou, a escolha dos governantes através do voto, é considerada essencial e defendida por ser uma condição necessária e fundamental do regime democrático e por que permite a responsividade e a escolha dos melhores governantes. Mas, por outro lado, a participação da população

\footnotetext{
${ }^{11}$ Como, na realização das entrevistas, garantimos que não haveria a identificação das opiniões e posições com os respectivos respondentes - condição importante para a disposição dos entrevistados em participar da pesquisa - a correlação entre as entidades, suas respectivas características e o conteúdo das respostas, bem como as comparações e desagregações ficam prejudicadas.
} 
OPINIÃO PÚBLICA, Campinas, vol. 18, n², novembro, 2012, p. 452 - 469

no processo decisório também é considerada essencial pela grande maioria dos entrevistados e as justificativas vão no seguinte sentido: a participação diz respeito à própria natureza do regime democrático; é necessário o controle sobre os governantes, por exemplo, através de conselhos comunitários; e a existência de uma postura cívica e da co-responsabilidade do cidadão é muito importante para a democracia. Embora haja quatro entrevistados que entendem que a participação não é essencial, eles não deixam de considerá-la desejável. Ou seja, nenhum dos entrevistados declarou que a participação é dispensável ou indesejável. No caso daqueles quatro entrevistados que apontaram não ser a participação essencial, os argumentos foram os seguintes: a participação poderia desprestigiar a democracia representativa, dado que os representantes têm, de um lado, condições institucionais - por exemplo, as assessorias técnicas -, e de outro, a própria pressão popular, o que os forçaria a tomar as melhores decisões; a democracia poderia e deveria ser exercida em muitos aspectos sem uma participação ampla da sociedade, ou seja, de forma restrita a grupos reduzidos, desde que qualificados tanto política quanto tecnicamente; e, por fim, porque a participação poderia, às vezes, conduzir a decisões erradas.

Apenas um dos entrevistados entende que a liberdade de mercado e de iniciativa não seria essencial, mas apenas desejável, ponderando que nem sempre esse seria o melhor caminho para a consolidação da democracia. Os demais justificam sua posição a partir das seguintes ponderações: trata. se de uma forma de dar competitividade à economia nacional; este tipo de liberdade, antes de qualquer coisa, é um preceito constitucional; por ser isso o sentido e o objetivo fundamental que a ação das entidades de representação empresarial deveria ter; e por ser uma forma de promoção do bem estar social ou mesmo a outra face da democracia.

A democracia é também considerada por todos como uma forma eficaz de resolver crises políticas e sociais, dado que estas decorreriam das escolhas erradas feitas pela própria sociedade, mas cujas soluções deveriam ser buscadas através da liberdade e da própria democracia. Há o entendimento de que a democracia tem a vantagem de ser um regime político aberto, com a ressalva de que a capacidade de administrar as crises existe se ela funcionar bem.

Por sua vez, a adesão da população aos valores democráticos é considerada essencial pelos entrevistados de forma unânime, pois quanto maior ela for, mais democrática e cívica será a sociedade e maior o controle desta sobre o governo. $\mathrm{E}$ o mesmo se atribui ao respeito às autoridades, mas não enquanto submissão, pois é fundamental questionar e cobrar as autoridades e mantê-las subordinadas ao voto. E, quando perguntados sobre qual é a autoridade mais importante, as respostas foram, de um lado, o "povo", e, de outro, o Presidente da República, ou o Presidente do Supremo Tribunal Federal, ou as "instituições" de um modo geral, dado que elas estabeleceriam os direitos e deveres dos cidadãos e também que o exercício da democracia implicaria no fortalecimento das instituições, através da crítica e da busca pelo seu aperfeiçoamento.

Ainda sobre as instituições, colocamos para os entrevistados a seguinte questão: o que é mais importante, o bom funcionamento das instituições políticas (Congresso Nacional, partidos políticos, sistema partidário, sistema eleitoral, etc.) ou das instituições econômicas (Banco Central, Banco do 
COSTA, P. R. N. A elite empresarial e as instituições democráticas: cultura política...

Brasil, Banco Nacional de Desenvolvimento Econômico e Social e agências reguladoras)? Com apenas uma exceção, as respostas apontaram para a primazia das instituições políticas, justificada pelo fato de que o bom funcionamento destas levaria à estabilidade e à governabilidade, o que, por sua vez, não só fortaleceria como seria uma condição para o bom funcionamento de todas as outras instituições, inclusive as econômicas, além de serem as instituições políticas a base da liberdade política individual ${ }^{12}$.

A competência administrativa dos governantes é considerada pelos entrevistados como essencial à democracia, mas tal posição é justificada pelo fato de que se trata de uma obrigação dos governos eleitos na democracia, e porque a incompetência governativa ou a politização da escolha dos ocupantes de cargos administrativos públicos enfraqueceria a democracia e a adesão popular a este sistema político. Houve quem declarasse que sua entidade atua na formação de quadros mais qualificados para o desempenho de funções tanto no setor público quanto no privado.

Em suma, os membros da elite empresarial brasileira aqui considerados mostram total adesão à democracia, justificada, geralmente, pelos seguintes fatores: a ênfase na necessidade da representação política, mas também do amplo debate e da participação dos cidadãos na condução dos assuntos públicos que este regime permite; por implicar em uma forma de sociedade mais justa, mesmo que a política possa trazer, juntamente com os benefícios coletivos, alguns prejuízos pessoais; porque a democracia seria necessária para o desenvolvimento da sociedade e a redução da desigualdade; por ser o contexto mais favorável à livre iniciativa e à liberdade individual e por comportar formas de solucionar eventuais crises. Por fim, os entrevistados defendem a necessidade da difusão de uma cultura política democrática e do bom funcionamento das instituições políticas para que o regime democrático se estabeleça e se desenvolva.

Quando perguntados sobre o funcionamento da democracia no Brasil, algumas opiniões apontaram para a sua imaturidade e para a necessidade de seu aprimoramento institucional. Outros entendem que ainda faltariam algumas reformas e aperfeiçoamentos, entre os quais o equilíbrio entre os poderes Executivo e Legislativo e a reforma política. Mas a maioria entende que a democracia no Brasil já está consolidada, por não sofrer ameaças de nenhum tipo, por suas situações críticas serem normais e também porque a população está mais atenta ao seu funcionamento.

Sobre o funcionamento concreto das instituições democráticas no Brasil, a Presidência da República foi bem avaliada, dado que tem promovido as estabilidades política e econômica, embora haja críticas pela falta de compromisso na realização das reformas necessárias. A avaliação também é relativamente positiva em relação ao Banco Nacional de Desenvolvimento Econômico e Social (BNDES), cujo mérito seria estabelecer critérios sustentáveis e transparentes de financiamento, mas há quem critique o banco por discriminar certos setores e favorecer outros, em especial os grandes projetos. 0 Banco Central é bem avaliado pela contribuição à estabilidade monetária, mas necessita ser efetivamente autônomo. Já o Banco do Brasil, na avaliação dos entrevistados, tem um desempenho apenas entre bom e satisfatório, dada a falta de transparência e de estabilidade interna, ou até

\footnotetext{
12 Tal resultado também foi verificado em pesquisa semelhante realizada em 2004 e 2005. Ver Costa (2007).
} 
OPINIÃO PÚBLICA, Campinas, vol. 18, n², novembro, 2012, p. $452-469$

insatisfatório, devido ao seu tamanho ou mesmo pelo fato de que seria praticamente um banco comum. Por sua vez, a avaliação dos ministérios é apenas satisfatória, em função de uma excessiva politização e da variação da competência dos ministros. As agências reguladoras ${ }^{13}$ têm um funcionamento ruim por serem muito politizadas, inócuas e sem funções claras.

Sobre as instituições políticas representativas, o desempenho dos partidos políticos é avaliado como ruim ou, no máximo, satisfatório; há alguns partidos bons e outros muito ruins, além da pouca densidade ideológica. O sistema partidário também é ruim ou, no máximo, satisfatório, implicando na necessidade da reforma política. Mas esta posição convive com certa confiança nos partidos e no sistema partidário e apenas certo descontentamento com a existência dos pequenos partidos. Já o sistema eleitoral tendeu a ser mais bem avaliado, mas houve críticas em relação à qualidade dos representantes eleitos. As associações patronais em geral são mais bem avaliadas - inclusive pelas entidades de natureza sindical, sendo que o inverso não ocorre ${ }^{14}$ - por serem mais dinâmicas, trazerem mais contribuições ao país e por que seriam fundamentais nas democracias.

Perguntados sobre a reforma política, as respostas indicam que o reconhecimento de sua importância vem acompanhado de certo ceticismo em relação à sua viabilidade. A justificativa de tal importância é ora de natureza ética, ou seja, a busca da redução da corrupção, ora a ênfase na necessidade de cobrar que ela seja feita pelo Congresso Nacional. A maior parte dos entrevistados declara que sua entidade tem se preocupado em atuar pela reforma das instituições políticas, em especial no que tange à liberdade de expressão, mas a maioria sinaliza que tal atuação tende a limitar-se à promoção de debates e estudos.

E em relação às questões que marcam o ainda incipiente debate sobre reforma política no Brasil, praticamente todos são contra o financiamento público de campanha por entenderem que não resolveria o problema da falta de transparência, de ética e de legitimidade. Na sua maior parte, os entrevistados defendem a permanência de uma reeleição para os cargos do poder Executivo. Em relação ao voto obrigatório - ora concebido como forma de fortalecimento da democracia no Brasil, ora visto como algo desnecessário, dada a natureza do regime democrático e o amadurecimento político da sociedade -, sofre a oposição da maior parte dos entrevistados. Há a defesa do voto distrital, misto ou com lista aberta, como forma de aumentar a responsividade e a qualidade da representação. Muito poucos são favoráveis a uma constituinte exclusiva para fazer a reforma política, argumentando que os parlamentares não poderiam legislar sobre suas próprias atividades ${ }^{15}$.

\footnotetext{
13 Nos referimos às agências que regulam os setores de telefonia (ANATEL), energia (ANEEL), aviação (ANAC), etc.

${ }^{14}$ As entidades sindicais, tanto de patrões quanto de empregados, foram mal avaliadas pelas entidades associativas, em função da adoção de práticas consideradas ultrapassadas, entre elas o chamado "Sistema 'S'”, e do predomínio de lideranças antigas. Obviamente, as opiniões favoráveis à estrutura de representação sindical em geral partiram das entidades desta natureza.

15 Isso talvez se deva também ao caráter incipiente desta proposta ou ao desconhecimento de seu conteúdo. A ideia de uma assembleia constituinte exclusiva para redefinir o funcionamento das instituições políticas, em especial o sistema partidário e o sistema eleitoral, possui algum apoio difuso entre os empresários e outros setores da sociedade brasileira, mas não foi além de alguns movimentos sem continuidade. Não há uma posição única sobre o assunto. Por exemplo, um dos entrevistados defende que os membros desta assembleia só poderiam disputar cargos políticos oito anos após o seu encerramento, como uma forma de separar, ainda que temporariamente, os responsáveis pela elaboração das novas regras políticas das disputas pelo poder.
} 
COSTA, P. R. N. A elite empresarial e as instituições democráticas: cultura política...

Quando tratamos da questão da confiança ${ }^{16}$, alguns aspectos gerais se revelam nas respostas dos entrevistados. Em primeiro lugar, no que tange às atividades propriamente empresariais, é quase unânime a ideia de que existe um alto grau de confiança entre os agentes. Este aspecto coaduna-se com a afirmação de que as ações das suas respectivas entidades, em geral, se dão de forma articulada com outras entidades, o que sugere que haveria certa cooperação.

Em segundo lugar, quando explicitamente questionados se, da mesma forma como a população em geral, eles avaliavam positivamente a democracia, mas negativamente o desempenho das instituições por excelência democráticas ${ }^{17}$, a maior parte respondeu afirmativamente, argumentando da seguinte forma: como não haveriam partidos políticos com posições definidas e como as regras para as eleições permitem a desfiguração da representação parlamentar, o funcionamento do regime democrático ficaria muito prejudicado e conduziria a "crises", como a do chamado mensalão, ou a composições espúrias para manter o funcionamento do governo. Se não existem dúvidas sobre a ideia de democracia, o comportamento das instituições ainda está muito ruim; o Congresso Nacional é submisso ao Executivo e o Judiciário excessivamente politizado; faltam órgãos fiscalizadores dos poderes constituídos; e, por fim, seria necessária uma "depuração", para tirar as pessoas ruins e manter o sistema político, que seria bom. Mas, ainda que em minoria, os demais entrevistados discordam desta avaliação negativa em relação às instituições democráticas, alegando que a convivência com o funcionamento cotidiano da democracia não impede a livre formação das opiniões e que tal avaliação depreciativa das instituições seria, em parte, devida à falta de informação por parte da população em geral, e, em parte, devida à influência negativa da mídia, dado que, por exemplo, no Legislativo federal, em geral alvo de críticas e insatisfações, haveria muitos parlamentares qualificados e uma estrutura institucional capaz de produzir bons resultados ${ }^{18}$.

Quando questionados sobre o grau de confiança nas instituições estatais e representativas, em primeiro lugar, o Executivo Federal tendeu a ser bem avaliado, o mesmo ocorrendo com o Executivo estadual (em especial as entidades estaduais), seja em função do desempenho no âmbito econômico, seja em função de um projeto geral para o país e projetos para áreas específicas, concorde-se ou não com tais projetos. Por sua vez, o nível de confiança nos poderes legislativos é baixo, em especial no âmbito estadual, mas isso não impediu a ocorrência de avaliações positivas, argumentando-se que são instituições e cargos eletivos, ou seja, de uma forma ou de outra passaram pelo controle da população através do voto e por isso mereceriam confiança. O Senado, em particular, foi um pouco mais bem avaliado, em função de sua maior estabilidade e profissionalização em comparação com a Câmara dos Deputados e com as Câmaras de Vereadores.

\footnotetext{
16 Entendemos que não há necessidade de aqui argumentar sobre a relevância desta questão na Teoria da Democracia e nas análises de suas experiências concretas. Para um debate atualizado e diversificado sobre esta questão, ver Moisés (2010).

17 A referência aqui é à "situação paradoxal" que, segundo Moisés e Carneiro (2010), caracteriza a democracia brasileira nos dias de hoje. Voltaremos a esta questão adiante.

${ }^{18}$ Estudos recentes parecem não corroborar a ideia de que o acesso às informações veiculadas pela mídia tem um papel decisivo na avaliação negativa das instituições democráticas entre a população em geral (MENEGUELLO, 2010; MESQUITA, 2010).

461
} 
OPINIÃO PÚBLICA, Campinas, vol. 18, n², novembro, 2012, p. 452 - 469

Em suma, esses dados indicam que o grau de confiança e satisfação da elite empresarial com as instituições democráticas é maior em comparação ao da população brasileira de um modo geral ${ }^{19}$. Voltarei a este assunto adiante.

Em relação aos padrões de ação política, os entrevistados declararam que as ações são, geralmente, articuladas com outras entidades ou empresas. Os contatos ocorrem predominantemente com os poderes e agências no nível federal. Presidência da República e mais intensamente os ministérios, secretaria e órgãos federais e o Senado ·, com os quais seriam tratados os interesses das empresas ou do setor representado pela entidade. As entidades com âmbito de ação estadual tendem a voltar-se mais para o Executivo estadual e para os senadores do estado. Os resultados dos contatos com as instituições políticas e com os diferentes níveis de governo, foram, em geral, avaliados positivamente e giram predominantemente em torno dos interesses mais imediatos dos representados.

Quanto às formas de representação empresarial, os entrevistados não apontaram que a criação de uma associação de cúpula (peak association) seja necessária, pois: já haveria entidades suficientes; cada tipo de entidade teria os seus próprios problemas e interesses; atualmente, diferentemente do que acontecia há alguns anos atrás, as entidades de um modo geral estão tratando não apenas suas questões paroquiais, mas também debatendo sobre as grandes questões nacionais; e que apenas faltaria uma maior coordenação das entidades que já existem. Mas, um grupo menor entre os entrevistados defendeu a necessidade de algo como o Conselho Patronal Francês ou a Keidanren no Japão, no sentido de defender as posições do setor privado frente aos poderes Executivo e Legislativo, e apenas um dos entrevistados mencionou a Ação Empresarial, coordenada por Jorge Gerdau Johannpeter, embora muitas das entidades contempladas por nossa pesquisa dela façam parte ${ }^{20}$.

De um modo geral, os entrevistados avaliam positivamente o papel dos empresários no funcionamento da sociedade brasileira pós-1988 e nas perspectivas futuras, mas entendem que eles deveriam ser mais participativos, unidos e pressionar mais pelas reformas que julgam necessárias.

\section{Considerações finais}

Um primeiro aspecto a ser observado é de ordem teórica e metodológica, qual seja, a importância de analisar os valores e as atitudes políticas das elites políticas frente à democracia, dada a contribuição que tal estudo tem para a compreensão das características destas elites, da sua ação política, das suas relações com as instituições democráticas e até do funcionamento destas últimas. Além disso, introduz no estudo daquela que seria a elite econômica a sua existência enquanto elite política, através da consideração de aspectos relativos à representação e à ação política.

O rendimento analítico da mobilização de variáveis relacionadas às concepções, opiniões e avaliações se dá na obtenção de informações sobre um dos elementos importantes para o momento da

\footnotetext{
${ }^{19}$ Ver Moisés (2010).

20 Esta entidade pretende defender os interesses do conjunto dos empresários brasileiros. Sobre a Ação Empresarial, ver: $<$ http://www.acaoempresarial.com.br/>.
} 
COSTA, P. R. N. A elite empresarial e as instituições democráticas: cultura política...

ação, ou da falta desta, frente às questões concretas, dado que se trata do julgamento a respeito das instituições políticas e das justificativas e valores subjacentes.

Estas informações podem indicar as tendências de aceitação, apoio, recusa ou contraposição por parte dos empresários em relação a certas características importantes do regime democrático vigente no Brasil, fornecendo hipóteses de trabalho mais bem fundamentadas e sugerindo os prováveis âmbitos e padrões nos quais se dariam as ações concretas do empresariado, bem como as possíveis contradições ou mudanças de posição (COSTA, 2007). Daí, a importância da utilização de métodos qualitativos, que busquem os fundamentos e as justificativas das atitudes e ações políticas.

Além disso, embora não possamos desenvolver todas as implicações da estratégia de análise aqui proposta, o interesse nesta abordagem alternativa da ação política do empresariado, por um lado, permite trabalhar questões mais próximas ao grupo ou classe social, e não apenas de suas instituições de representação, exatamente por tratar da questão da representação política, dimensão fundamental na análise da ação coletiva, e permite comparações com a relação que a população em geral e outros grupos sociais em particular têm com as instituições democráticas ${ }^{21}$.

E, por outro lado, um foco de análise do empresariado centrado na política econômica tenderia a concentrar-se na relação entre este grupo e o âmbito federal do processo decisório, em especial, o poder Executivo, deixando de lado outros espaços importantes da ação política do empresariado e do próprio funcionamento da política nas democracias e, principalmente, do próprio Estado e do Governo, como os Governos estaduais, as Assembleias Legislativas e as Prefeituras. Por fim, a análise da posição do empresariado frente à questão das instituições políticas permite problematizar sob outra ótica aspectos da sua adesão tanto à democracia quanto à "ideologia liberal stricto sensu" (DINIZ e BosCHI, 2004, p. 32). Enfim, é possível verificar se o empresariado é ou deixa de ser liberal não apenas no que diz respeito à relação entre Estado e mercado, mas também em relação aos fundamentos da democracia. Como apresentado anteriormente, se ainda há dúvidas quanto à adesão da elite empresarial brasileira em relação à efetivação de pressupostos liberais no que diz respeito às relações entre economia e Estado, isso não ocorre em relação à adesão aos pressupostos liberais da democracia como regime político.

Em segundo lugar, dentro dos limites de nossa pesquisa, enunciamos a seguir as principais conclusões a que podemos chegar a respeito dos valores em relação à democracia e dos padrões de ação política por parte da elite empresarial brasileira.

Verificamos anteriormente que os membros da elite empresarial têm hoje uma posição intensamente mais favorável ao exercício da política, em comparação ao que apresentavam até meados dos anos 1990 (COSTA, 2005a; 2005b), e uma forte adesão à democracia, muito maior do que a da população brasileira em geral ${ }^{22}$. Mas o que convém destacar é que as justificativas apresentadas pelos entrevistados para tal adesão não destoam daquilo que podemos considerar como as características

\footnotetext{
${ }^{21}$ A título de exemplo, é possível comparar os resultados obtidos com os de pesquisas feitas em outros grupos menores, como a análise das ideias dos jornalistas, feita por Marcelino et al (2010).
}

22 Sobre isso, ver Moisés e Carneiro (2010). 
OPINIÃO PÚBLICA, Campinas, vol. 18, nº 2, novembro, 2012, p. $452-469$

fundamentais deste regime político, ou seja, a valorização do debate público e da participação, da responsividade e da eficácia governamental como forma de promoção do bem estar da população e, ao mesmo tempo, sedimentação da própria democracia. A relevância deste aspecto é destacada por Dahl, que chamava a atenção para a importância da adesão dos "ativistas políticos" à democracia para o sucesso da democratização e da própria poliarquia (DAHL, 1997). Há também uma relação de justificação entre democracia e a liberdade econômica e de mercado, mas que ficou em segundo plano. Enfim, os entrevistados reconhecem que a democracia implica tanto em consenso quanto em conflitos, ou seja, uma postura mais realista e uma visão menos gerencial ou pragmática em relação ao que se poderia esperar da política na democracia, quando comparada àquela que existia nos anos 1990 (COSTA, 2005a; 2005b). Isso significa que hoje a elite empresarial aceita mais facilmente a ideia de que a democracia é uma forma de administrar conflitos de interesses e não simplesmente uma questão de bom gerenciamento de recursos e pessoas. Além disso, a importância dada à adesão da população aos valores democráticos mostra que aquela elite considera a cultura política democrática, ao lado de uma cultura cívica mais participativa, como algo decisivo para o sucesso da democracia no Brasil, ao lado de outros aspectos como a estabilidade político-institucional, a eficácia governativa e a redução da desigualdade.

Em relação à questão da participação da população no processo político, os entrevistados não estabelecem uma correlação negativa com o bom funcionamento da democracia, mas ao contrário, tenderam a associar espontaneamente uma coisa à outra. E mesmo quando afirmam que a participação não seria essencial, mas apenas desejável, o argumento não destoa da preocupação expressa por autores clássicos e contemporâneos da Teoria da Democracia, de Tocqueville a Weber, de Schumpeter a Manin, ou seja, que a democracia necessita de algumas dimensões aristocráticas, ou seja, não subordinadas à deliberação coletiva e restrita a um corpo de técnicos ou de representantes, como forma de obter eficácia e evitar os vícios deste regime político. Apesar da simpatia declarada com a participação política da população, a maior parte dos respondentes indicou que exerce pouco empenho efetivo no sentido de fomentar ou participar de iniciativas que promovam as formas de participação política ${ }^{23}$. A nosso ver, isso guarda relação com a questão da satisfação desta elite com as instituições da democracia brasileira, como veremos quando tratarmos dos padrões de ação política.

Quando comparamos os valores e atitudes com os padrões de ação política declarados pelos entrevistados, verificamos que o grau de confiança, tanto nas atividades empresariais, como nas instituições políticas coaduna-se com a declaração de que as ações das entidades são feitas em geral de forma articulada ao invés de isolada. Isso remete à questão da confiança.

Em relação a esta questão, verificamos que entre os membros da elite empresarial entrevistados, além do declarado alto grau de confiança nas relações empresariais, existe uma avaliação positiva da consolidação da democracia no Brasil e a conviç̧ão de que suas instituições são o melhor

23 Uma ação promovida por entidades de representação empresarial para o fomento da participação política da população em geral, e não apenas do empresariado, é a Rede de Participação Política, criada e sustentada pela Federação das Indústrias do Paraná (FIEP) e pela Federação das Associações Comerciais do Estado do Paraná (FACIAP). Seja como for, esta é ainda uma experiência isolada e inédita no âmbito deste tipo de entidade. Sobre a Rede, ver Costa e França (2012). 
COSTA, P. R. N. A elite empresarial e as instituições democráticas: cultura política...

caminho para solucionar eventuais crises. Isso revela mais do que simplesmente um alto grau de adesão à democracia, mas também uma confiança relevante em suas instituições.

Quando consideramos mais especificamente as posições frente às instituições políticas, estatais ou representativas, em primeiro lugar, observamos que os graus de confiança e de satisfação com os partidos políticos e com o poder Legislativo, em geral, são baixos, se comparados ao Executivo, mas é maior do que, por exemplo, nas ONGs. Embora a avaliação do desempenho das instituições econômicas tenha sido mais positiva do que a das instituições políticas, essas últimas foram consideradas mais importantes pelos entrevistados. Enfim, verificamos a ocorrência de uma situação distinta daquela constatada por Moisés e Carneiro (2010) e Meneguello (2010) em relação à população brasileira. Para estes autores, o Brasil caracterizar-se ia por uma "situação paradoxal", ou seja, apesar do apoio majoritário ao regime democrático, quase $2 / 3$ dos brasileiros não confiam nas instituições políticas. Nossa pesquisa sugere que, além de uma adesão unânime à democracia, a elite empresarial, enquanto parte da elite política, parece estar muito menos insatisfeita e mais confiante nas instituições do que a população em geral.

Em segundo lugar, as críticas e insatisfações da elite empresarial com as instituições representativas apontam para a falta de solidez programática dos partidos e a submissão do Legislativo ao Executivo, mas estão longe de indicar a defesa de uma democracia sem partidos ou sem Parlamento, como acontece com a população em geral, também segundo Moisés e Carneiro (2010). As justificativas remetem à preocupação com a qualidade da representação e do processo decisório, que é um problema crucial, em maior ou menor grau, de todas as experiências históricas de democracia, mesmo as mais bem sucedidas. Enfim, as respostas sugerem certa capacidade de ver o funcionamento das instituições democráticas enquanto um processo ainda em andamento e de distinguir tais instituições das pessoas que as ocupam e do seu funcionamento em um dado momento.

Além disso, entendemos que o aspecto fundamental da articulação entre os valores e as avaliações sobre as instituições políticas brasileiras por parte da elite empresarial aparece quando verificamos alguns aspectos de seus padrões de ação política. Este é outro ganho analítico decorrente da metodologia da pesquisa subjacente ao trabalho relatado neste artigo, ou seja, articular os valores políticos com os padrões de ação política. Quando consideramos as declarações de que as ações junto a tais instituições, em especial no poder Executivo nos âmbitos federal e estadual, tendem a ser bem sucedidas, constatamos que o grau de satisfação com os resultados das ações junto às instâncias do poder estatal indicam um grau maior de responsividade das instituições políticas em relação aos interesses representados pelas entidades empresariais, portanto, um desempenho institucional melhor em relação a tais interesses, em comparação com a população em geral. E podemos acrescentar que se trata de algo que se refere à accountability horizontal, na forma como ela é pensada por O'Donnell (1991; 1998) e Morlino (2010), ou seja, para além da accountabulity vertical, que tende a se restringir ao 
OPINIÃO PÚBLICA, Campinas, vol. 18, nº 2, novembro, 2012, p. $452-469$

processo de escolha de representantes e governantes, e remete à dimensão mais propriamente republicana da democracia e ao atendimento dos interesses dos representados pelas suas instituições ${ }^{24}$.

Os dados tendem também a corroborar a conclusão de Bishin, Barr e Lebo (2006) que aponta que o desempenho das políticas econômicas adotadas pelo Presidente da República é um elemento fundamental do apoio das elites à democracia. Isso pode ser verificado pela avaliação positiva, e suas respectivas justificativas, sobre a atuação da Presidência da República.

Mas as posições dos membros da elite empresarial aqui considerados indicam que, de um lado, suas avaliações sobre as instituições democráticas podem distinguir-se não apenas da população em geral, mas também do próprio conjunto dos empresários, dado que se trata de uma elite política, ou seja, de indivíduos muito mais afeitos à prática do jogo democrático e do funcionamento das instituições que caracterizam este tipo de regime político, em especial no que diz respeito ao processo de representação política. E, de outro, sugere que a satisfação das elites políticas com as instituições democráticas é muito mais relevante do que aquela encontrada entre a população em geral para a estabilidade da democracia.

Trata-se de um aspecto muito complexo e que vai muito além dos limites da pesquisa aqui reportada, mas que levanta a hipótese de que a democracia brasileira, como todas as demais, tem mais chance de permanecer estável sem a satisfação de sua população em geral com as suas instituições, do que com o mesmo juízo entre as elites políticas da sociedade. Por fim, as posições dos membros da elite empresarial brasileira corroboram a proposição de Meneguello sobre a necessidade de se aprofundar e se tratar com mais precisão o conceito de "satisfação" para o estudo da democracia brasileira (MeneGuelLo, 2010). Em relação a este aspecto, nossa pesquisa sugere alguns pontos. De um lado, o grau elevado de adesão à democracia não significa satisfação igualmente elevada de todos os seus cidadãos com suas instituições, ainda mais quando se trata de uma democracia jovem e em consolidação como a brasileira, na qual os avanços no funcionamento da democracia têm que ser acompanhados de aprimoramentos nas instituições econômicas e aprofundamento da distribuição de renda e bem estar. Nossos dados indicam que a insatisfação ou a crítica aparece também em relação às instituições econômicas, ou seja, assim como as instituições políticas as econômicas também necessitariam de aperfeiçoamentos que levassem a um grau maior de satisfação, e isso por parte de uma elite que está diretamente ligada a este âmbito do funcionamento da sociedade.

Ainda sobre os padrões de ação política do empresariado, há uma tendência a reforçar as características gerais do sistema político, como, por exemplo, a primazia da agenda focada no Executivo, em especial no nível federal, apesar da defesa de uma relação mais equilibrada entre este poder e o Legislativo. Estas proposições são corroboradas por alguns estudos recentes sobre a ação política do empresariado ${ }^{25}$ e fundam-se também na tendência da crítica e do descontentamento com as formas vigentes de nossa democracia, com raras exceções, não ser acompanhada de ações concretas voltadas

24 O’Donnell aponta também que ocorre accountability horizontal quando as instituições regulam e mostram para o "ator racional" os custos das atitudes impróprias, ou seja, um processo de aperfeiçoamento do funcionamento das instituições democráticas tanto por parte das instituições quanto dos atores (O'DONNELL, 1991).

${ }^{25}$ Ver, por exemplo, Oliveira e Onuki (2010). 
COSTA, P. R. N. A elite empresarial e as instituições democráticas: cultura política...

para reformulação das instituições do regime político democrático brasileiro. Isso confirma que a atuação dos empresários no processo de construção e funcionamento das instituições democráticas no Brasil se dá menos pela ação, e mais pela falta desta (COSTA, 2005a, 2005b e 2008), além de corroborar a ideia de que a elite empresarial está mais satisfeita do que insatisfeita com a democracia brasileira e suas perspectivas.

Apesar de não termos explorado as possíveis relações entre os tipos de entidade e as opiniões dos entrevistados, os dados indicam uma grande coesão em relação a diversos aspectos relacionados à natureza da democracia e ao seu funcionamento no Brasil. Além disso, tais posições são corroboradas por algumas das opiniões de importantes empresários, como Antonio Ermírio de Moraes, Benjamin Steinbruch e Emílio Odebrecht ${ }^{26}$. Este aspecto indica que, dada a diversidade das entidades cujos representantes foram entrevistados, a extensão da pesquisa e a consideração de um número muito maior de entidades tenderia apenas a confirmar esta coesão e a semelhança dos posicionamentos nos seus aspectos gerais e essenciais, o que não significa que não haja divergências e que elas não sejam sociologicamente relevantes.

Por fim, é fundamental também termos claro que os resultados apresentados pelas entrevistas referem-se a atitudes e declarações, as quais em geral estão carregadas de desejos e de referência ao que se entende que a ação política do empresariado e a democracia brasileira deveriam ser, processo bastante conhecido dos estudos sobre cultura e atitudes políticas. Daí a importância da análise da ação política concreta, apenas parcialmente contemplada pela pesquisa reportada neste artigo. Desta forma, poderíamos verificar a pertinência das indicações sugeridas pela atual pesquisa, como, por exemplo, se a elite empresarial será mais ou menos pragmática na definição e no exercício do seu papel político; se partilhará uma visão da política como uma questão gerencial e estritamente voltada para a economia; se será mais ou menos ativa ou reativa; se assumirá ações de curto prazo, pulverizadas, setorizadas e fragmentadas, ou unificadas, amplas e prospectivas; se dará maior ou menor importância, através de ações concretas e contundentes, à reforma das instituições políticas; se estará mais ou menos próxima das forças políticas e partidárias defensoras de reformas sociais ("esquerda"); se assumirá posturas mais ou menos liberais, seja quanto à relação entre Estado e mercado, seja quanto aos pressupostos da democracia.

Especulando-se sobre as tendências da ação política da elite empresarial brasileira a partir dos resultados de nossas pesquisas, é possível dizer o seguinte: 1 - ainda que a elite empresarial mantenha um alto grau de adesão à democracia, tal adesão tenderia a levar em conta o desempenho das instituições, não só econômicas, mas também políticas, e em relação não apenas aos seus interesses, o que é normal e legítimo em uma democracia, mas também em relação aos que seriam os interesses de toda sociedade; 2. haveria uma tendência crescente, ainda que lenta, a uma atuação mais intensa por parte dos empresários na política, mesmo que isso não implique em um número maior deles atuando

26 Sobre as opiniões de Moraes, ver Folha de São Paulo, 20/08/2006, 01/10/2006 e 16/09/2007. Para as opiniões de Steinbruch, ver Folha de São Paulo, 11/08/2009 e 29/12/2009. E para Emílio Odebrecht, ver Folha de São Paulo de 21/02/2010 e 27/06/2010. 
OPINIÃO PÚBLICA, Campinas, vol. 18, n², novembro, 2012, p. 452 - 469

diretamente em cargos políticos, eletivos ou não; 3. em um contexto de reforma das instituições políticas, a elite empresarial tenderia a defender a manutenção da reeleição para os cargos do Poder Executivo, o voto distrital, o fim do voto obrigatório e a fidelidade partidária, mas teria pouco interesse em uma reforma política através de uma constituinte exclusiva; 4. esta elite defenderia a normalidade democrática como forma de solução de eventuais crises e 5. não teria muito interesse na construção de uma peak association que representasse o conjunto do empresariado. Como vimos anteriormente, este aspecto é importante dado que alguns trabalhos sobre a ação política do empresariado brasileiro (DINIZ \& BosCHI, 2004; 2007; MANCUSO, 2007; SCHNEIDER, 2004) apontam para a ausência deste tipo de entidade como uma explicação dos padrões de ação política do empresariado e como um dos maiores problemas em relação ao papel e à força deste grupo na história e na sociedade brasileira. Em relação a isso, apesar dos limites estatísticos da pesquisa aqui relatada, observamos que os próprios empresários pensam de forma diferente, o que nos leva a considerar que, caso houvesse algum movimento neste sentido, dificilmente ele partiria dos próprios empresários e, caso o Estado tivesse tal iniciativa, teria dificuldade em efetivá.la. Embora esta discussão transcenda em muito aquilo que tratamos neste artigo, isso sugere também que a análise do processo de constituição das formas de representação de classe no Brasil não pode deixar de considerar a participação e o comportamento dos grupos sociais, em especial das chamadas categorias econômicas e, portanto, estaria longe de ser um processo exclusivamente via estatal.

Enfim, não estamos prognosticando os padrões e o conteúdo das ações políticas da elite empresarial brasileira em relação à democracia e suas instituições, nem afirmando que o conjunto desta classe social agiria desta forma. Mas, é possível reconhecer que há um arranjo de atitudes extremamente favoráveis a este tipo de regime político por parte da elite de uma classe social fundamental na sociedade capitalista e que, no caso brasileiro, já esteve entre as bases sociais de experiências autoritárias.

Ao contrário de uma aposta no papel desta elite na sustentação e no aperfeiçoamento da democracia brasileira, o que este artigo sugere é a necessidade de que o estudo aqui apresentado seja complementado com o estudo das ações efetivas da elite empresarial brasileira em situação concretas, lembrando que a ausência daquelas, ou seja, a falta de ação é, tanto política quanto sociologicamente, bastante relevante, pois indica a possibilidade da satisfação com o arranjo institucional.

Por último, a articulação entre os estudos de cultura política, em especial com uma abordagem qualitativa que permita verificar as justificativas das posições, e aqueles voltados para a ação concreta das elites políticas, ainda podem ser mais bem explorados pelos pesquisadores e apresentam-se como uma contribuição à Sociologia Política da democracia no Brasil, permitindo não apenas testar as avaliações dos especialistas e do senso comum quanto ao poder da elite empresarial brasileira sobre a política na democracia brasileira, mencionadas anteriormente, como também baseando a realização de estudos comparados futuros. 
COSTA, P. R. N. A elite empresarial e as instituições democráticas: cultura política...

\section{Referências Bibliográficas}

BAROMETRo EmPreSARIAL. VIII Encuesta Anual a Líderes Empresariales, Grupo de Opinión Pública de la Universidad de Lima, Lima, Peru, 2006.

BISHIN, B. G., BARR, R. R. and LEBO, M. J. "The impact of economic versus institutional factors in elite evaluations of presidential progress toward democracy in Latin America". Comparative Political Studies, vol. 30, n 10, 2006.

Costa, P. R. N. "Empresariado, regime político e democracia: Brasil, anos de 1990". Revista Brasileira de Ciências Sociais, São Paulo, vol. 20, n57, p. 109-126, fev. 2005a. p.422.449, out. 2005b. $\mathrm{n}^{\circ} 28$, jun. 2007

"Empresariado, instituições democráticas e reforma política". Revista de Sociologia e Política, Curitiba,

Costa, P. R. N. e Engler, I. J. F. "Elite empresarial: recrutamento e valores políticos (Paraná, 1995-2005)". Opinião Pública, Campinas, vol.14, n², nov. 2008

Costa, P. R. N. e FrançA, A. S. T. Da Responsabilidade Social à Responsabilidade Política: uma análise da Rede de Participação Política. In: CostA, A. J. D. et al. Estado, Empresas e Empresários: Agentes de Desenvolvimento. Editora CRV, Curitiba, 2012.

DAHL, R. A. Poliarquia. São Paulo: Edusp, 1997.

DINIZ, E. e BoschI, R. Empresários, interesses e mercado: dilemas do desenvolvimento no Brasil. Belo Horizonte/Rio de Janeiro: Editora UFMG/IUPERJ, 2004.

A difícil rota do desenvolvimento: empresários e a agenda pós-neoliberal. Belo Horizonte/Rio de Janeiro: UFMG/IUPERJ, 2007.

Mancuso, W. P. "O empresariado como ator político no Brasil: balanço da literatura e agenda de pesquisa". Revista de Sociologia e Política, Curitiba, $n^{\circ} 28$, jun. 2007.

Marcelino, D., Rennó, L., Mendes, R. e Gramacho, W. "A cabeça do jornalista: opiniões e valores políticos dos jornalistas no Brasil”. Comunicação \& Política, vol. 27, n³, p.13.42, 2010.

MESQUITA, N. C. Jornal Nacional, democracia e confiança nas instituições democráticas. In: MoIsés, J. A. (org.). Democracia e confiança: porque os cidadãos comuns desconfiam das instituições públicas? São Paulo: Edusp, 2010.

Meneguello, R. Aspectos do desempenho democrático: estudo sobre a adesão à democracia e avaliação do regime. In: MOISÉS, J. A. (org.). Democracia e confiança: porque os cidadãos comuns desconfiam das instituições públicas? São Paulo: Edusp, 2010.

MoIsÉs, J. A. (org.). Democracia e confiança: porque os cidadãos comuns desconfiam das instituições públicas? São Paulo: Edusp, 2010.

MoIsÉs, J. A. e CARNEIRO, G. P. Democracia, desconfiança política e insatisfação com o regime - o caso do Brasil. In: MoIsÉs, J. A. (org.). Democracia e confiança: porque os cidadãos comuns desconfiam das instituições públicas? São Paulo: Edusp, 2010.

MORLINO, L. Teoria da democratização, qualidade da democracia e pesquisa d opinião: ainda em "mesas separadas". In: Moısés, J. A. (org.). Democracia e confiança: porque os cidadãos comuns desconfiam das instituições públicas? São Paulo: Edusp, 2010.

O’DonnelL, G. “Democracia delegativa”. Novos Estudos Cebrap, São Paulo, n 31, 1991.

. "Accountability horizontal". Agora, Buenos Aires, número 8, 1998.

OlIVEIRA, J. A. e ONUKI, J. Política comercial e Legislativo: a atuação do empresariado brasileiro, In: MANCUSo, W. et al (orgs.). Estado empresariado e desenvolvimento no Brasil. São Paulo: Cultura, 2010.

SCHNEIDER, B. R. Business Politics and the State in Twentieth.Century Latin America. Cambridge: Cambridge University Press, 2004.

Paulo Roberto Neves Costa - paulocostaufpr@gmail.com

Submetido à publicação em julho de 2011. Versão final aprovada em janeiro de 2012. 